\title{
Study Habits of Urology Residents in Saudi Arabia: Identifying Defects and Areas for Curricular Development - A Trainee-Based Survey
}

This article was published in the following Dove Press journal:

Advances in Medical Education and Practice

\author{
Mohammad Alkhamees (D) \\ Meshari A Al-Zahrani (D) \\ Sulaiman Almutairi' \\ Hammam Alkanhal' \\ Mana Almuhaideb (iD) ${ }^{2}$ \\ Saad M Abumelha $\mathbb{D i}^{3-5}$ \\ 'Department of Urology, College of \\ Medicine, Majmaah University, Al- \\ Majmaah, Saudi Arabia; ${ }^{2}$ College of \\ Medicine, King Saud University, Riyadh, \\ Saudi Arabia; ${ }^{3}$ Division of Urology, \\ Department of Surgery, Ministry of the \\ National Guard - Health Affairs, Riyadh, \\ Saudi Arabia; ${ }^{4}$ King Abdullah \\ International Medical Research Center \\ (KAIMRC), Riyadh II426, Saudi Arabia; \\ ${ }^{5}$ College of Medicine, King Saud Bin \\ Abdulaziz University for Health Sciences \\ (KSAU-HS), Riyadh II426, Saudi Arabia
}

Correspondence: Mohammad Alkhamees Department of Urology, College of Medicine, Majmaah University, AlMajmaah I 1952, Saudi Arabia

Tel +966-554463808

Fax +966-164042500

Email m.alkhamees@mu.edu.sa
Purpose: This study evaluated the study habits of Saudi urology residents throughout their residency training. It examines the study time and quality of study materials used by Saudi urology residents and identifies ways to maximize study benefits.

Patients and Methods: An online questionnaire was distributed to 152 registered residents in regions throughout Saudi Arabia (response rate: 93.4\%). The questionnaire addressed study habits throughout training, motivations for studying, preferred study resources, impressions on teaching quality, study preparation methods, and exam preparedness among junior and senior residents.

Results: Among all residents, 37.3\% read for 2-5 hours weekly. Juniors read significantly more than seniors $(\mathrm{P}=0.034)$. Marital status affects seniors' study habits $(\mathrm{P}=$ 0.029). For most seniors, preparation for the final board exam is the greatest motivation for studying $(\mathrm{P}=0.006)$. The AUA/EAU guidelines were useful information source for seniors $(P=0.001)$. Fifty-four percent $(54.4 \%)$ of residents felt that their residency program did not provide protected study time prior to the board exams. Moreover, the majority $(64.8 \%)$ felt that the training program did not adequately prepare them for the board exams.

Conclusion: We recommend that local program directors implement more effective teaching methods. Structured reading habits and specific study materials were found to be positive predictors of successful performance. Residents should also be educated in balancing working hours, social life, and study.

Keywords: resident, study habits, Saudi Arabia, urology

\section{Plain Language Summary}

- We evaluated the study habits of urology residents in Saudi Arabia with focus upon their study time and the quality of their studying recourses.

- We distributed an online survey to all 152 registered urology residents in Saudi Arabia; 142 residents completed the survey.

- According to our data, weekly reading hours are below average among all residents: only $37.3 \%$ of them read for $2-5$ hours weekly.

- Junior residents read more than their senior collogues; marriage adversely affected the study hours of all residents.

- Senior residents said that preparing for the final board exam was the most important motive for studying.

- The majority of residents said that their residency training program failed to provide protected study time and to prepare them adequately for the board exams. 
- The results of this study reveal that study habits among Saudi Arabian urology residents feature significant deficiencies; the country's scientific and supervising training committees need to implement more effective teaching methods.

\section{Introduction}

Since residents must acquire both clinical and factual knowledge during their residency programs, it is important that they keep up with their medical fields. ${ }^{1}$ Residency training in urology has been well established in Saudi Arabia for the past two decades and already has a strong structural setup. The five-year residency is marked by specific training goals, and many different assessment approaches are used based on the latest updates from the Saudi board urology curriculum 2014. ${ }^{2}$ However, hospital-based residencies also entail long, often irregular working hours that along with personal life can limit opportunities for study time. Although several studies have examined study habits among surgical residents, ${ }^{3-8}$ research on the study habits of surgical subspecialties remains limited, particularly outside of Western contexts. This study extends the research by examining the average time spent studying by Saudi urology residents, as well as their materials used, perceptions of teaching quality, preferred study methods, and perceptions of board exam preparedness. Attitude and approach to learning, including study habits and selection of study resources, are known to be key factors in predicting students' professional success. ${ }^{9}$ Focusing on study habits, test-taking skills, surgical skills laboratories, and clinical mentorship during internship will lead to more success later in the residency. A successful resident is one with appropriate clinical performance and an objective measure of knowledge. ${ }^{10}$ In addition to the increasing demands of clinical care, residents are expected to master a large bulk of factual knowledge and skills during their residency. ${ }^{1}$

To our knowledge, no data currently exist on how Saudi urology residents study for their Board examinations. Therefore, this study evaluates this topic based on self-reported surveys administered to Saudi urology residents.

\section{Patients and Methods}

This study was based on a cross-sectional, anonymous, self-reported survey adopted from Skinner et al. ${ }^{3}$ The study was approved by the Institutional Review Board of Ministry of Health (Approval \# 2019-0124E). After being informed about the purpose of the study, all participants gave consent, and participant anonymity was ensured. The electronic-based survey was distributed via email to 152 urology residents of different Saudi hospitals registered in Saudi Commission for Health Specialties (SCFHS) between September and December 2019. During this period, the study investigators had sent reminders to the physicians reminding them of the research study after which they closed the data collection session and moved on to the data analysis process. The survey comprised 43 questions (42 closed-ended questions rated on a 5-point Likert scale and one yes/no question). Residents rated the volume of study, sources of motivation, resources used, study methods, and overall satisfaction with teaching quality. Questions addressed two distinct levels of training: junior resident and senior resident. For ease of reporting, the results presented are those that reflect high importance, grouped by training year (junior and senior resident).

Statistical analysis was conducted on the quantitative data using the SPSS program. Cronbach's alpha to measure item reliability showed acceptable reliability (0.732). Differences between postgraduate year (PGY) residents level as following: junior residents (PGY1, PGY2, PGY3) and senior residents (PGY4, PGY5) were analyzed by chi square test, while Fisher's exact test was used to examine the relationships among variables. The significance level was set at $P \leq 0.05$.

\section{Results}

Questionnaire data were received from 142 (93.4\%) residents with a mean age of 28.68 years (standard deviation of 2.34). Respondents' characteristics are shown in Table 1.

Most respondents reported studying for 2-5 hours weekly, with the majority studying up to 10 hours, and the minority for 10-40 hours (aggregated percentages). No one reported reading $>40$ hours per week (Figure 1). A Chi-square test showed that juniors read more than seniors $(P=0.034)$.

Using Fisher's exact test, we examined if there is any significant correlation between marital status or raising children and weekly study hours (Table 2). While no significant correlation was found between marital status and weekly study hours among juniors $(P=0.263)$, there was a significant correlation among seniors $(P=0.029)$. There was no significant correlation between raising children and weekly study hours among all residents (junior or senior $)(P=0.584$ vs 0.191$)$. 
Table I Demographic Data for Entire Sample

\begin{tabular}{|c|c|c|c|}
\hline & $\mathbf{n}$ & Mean & $\begin{array}{l}\text { Std. } \\
\text { Dev }\end{array}$ \\
\hline \multirow[t]{2}{*}{ Age (Years) } & 142 & 28.68 & 2.34 \\
\hline & & $\mathrm{n}$ & $\%$ \\
\hline \multirow[t]{2}{*}{ Gender } & Male & 137 & 96.5 \\
\hline & Female & 5 & 3.5 \\
\hline \multirow[t]{3}{*}{ Marital status } & Single & 54 & 38.0 \\
\hline & Married & 85 & 59.9 \\
\hline & Divorced & 3 & 2.1 \\
\hline \multirow[t]{2}{*}{ Raising children } & Yes & 88 & 62.0 \\
\hline & No & 54 & 38.0 \\
\hline \multirow[t]{5}{*}{ Current residency level } & PGY-I & 12 & 8.5 \\
\hline & PGY-2 & 37 & 26.1 \\
\hline & PGY-3 & 39 & 27.5 \\
\hline & PGY-4 & 24 & 16.9 \\
\hline & PGY-5 & 30 & 21.1 \\
\hline \multirow[t]{2}{*}{ Residency level } & Junior & 88 & 62.0 \\
\hline & Senior & 54 & 38.0 \\
\hline \multirow[t]{9}{*}{$\begin{array}{l}\text { Current urology residency } \\
\text { program }\end{array}$} & $\begin{array}{l}\text { Central region } \\
\text { (Riyadh) }\end{array}$ & 63 & 44.4 \\
\hline & Eastern region & 18 & 12.7 \\
\hline & Makkah & 4 & 2.8 \\
\hline & Jeddah & 18 & 12.7 \\
\hline & Al-Madinah & 8 & 5.6 \\
\hline & & 7 & 4.9 \\
\hline & $\begin{array}{l}\text { Asir/Southern } \\
\text { region }\end{array}$ & 17 & 12.0 \\
\hline & Other & 7 & 4.9 \\
\hline & Total & 142 & 100 \\
\hline
\end{tabular}

Using Fisher's exact test, the most influential factor motivating seniors to study was the final board exam $(P=0.006)$, while that for juniors was preparation for the operating room (OR). For both groups, the least motivating factor was preparation for their clinics (Figure 2).

The most useful study source comprised digests and study notes (but not at a significant level), followed by the Campbell-Walsh Urology textbook and American Urological Association (AUA)/European Urological Association (EAU) guidelines books (Figure 3). Using a Chi-square test and Fisher's exact test, no significant differences were found in resource use between juniors and seniors except that seniors found AUA/EAU guidelines more useful $(P=0.001)$ than juniors. Urology journals, Journal Club (JC) meetings, and review courses were the least useful study sources for both groups.
The most preferred study method (Figure 4) among seniors was independent study followed by interactive teaching and review courses, while interactive teaching was most preferred among juniors followed by independent study and review courses. Group study and dedicated lectures were the least preferred options for both groups. However, no significant values were found for any of the study methods in either group.

Residents were asked about their satisfaction level with teaching quality (Appendix 1). The highest level of satisfaction was with teaching quality in the operating room $(52.4 \%)$ followed by the role of senior resident/fellow in teaching $(42.9 \%)$. The lowest satisfaction was with morbidity and mortality conferences and Journal Clubs (10.1\%).

The most common study preparation habit for both groups was to take study leave $(69.8 \%)$, followed by coffee drinking to enhance concentration $(63.1 \%)$. The least common habits were to stay up all night (22.1\%) and to perform physical exercise before studying (22.8\%). Among all habits, a Chi-square test and Fisher's exact test found no statistically significant differences between groups (Appendix 2).

Most respondents reported that continuing on-call duties while studying was a major factor negatively affecting their performance on board exams $(63.8 \%)$, while inadequate clinical exposure during residency was the factor with the least negative effect (32.2\%). Among all negative factors, a Chi-square test and Fisher's exact test found no statistically significant differences between groups (Appendix 2).

The final section of the survey evaluated residents' opinions on the residency program and preparedness for the board exam (final and promotion exam). Overall, 76 $(53.5 \%)$ respondents disagreed that the residency program provided them with protected time for studying prior to the board exams. The majority $(92,64.8 \%)$ felt that the training program inadequately prepared them for the exams.

\section{Discussion}

As the first study to discuss the study habits of urology residents in Saudi hospitals, this study has applications for the design of future learning experiences. Below, we discuss in detail the many factors affecting urology residents and their study habits based on the survey responses.

\section{Age, Gender Differences and Study Habits}

Saudi Arabia is a youthful country with a high percentage of young people leading improvement in all fields of work as 


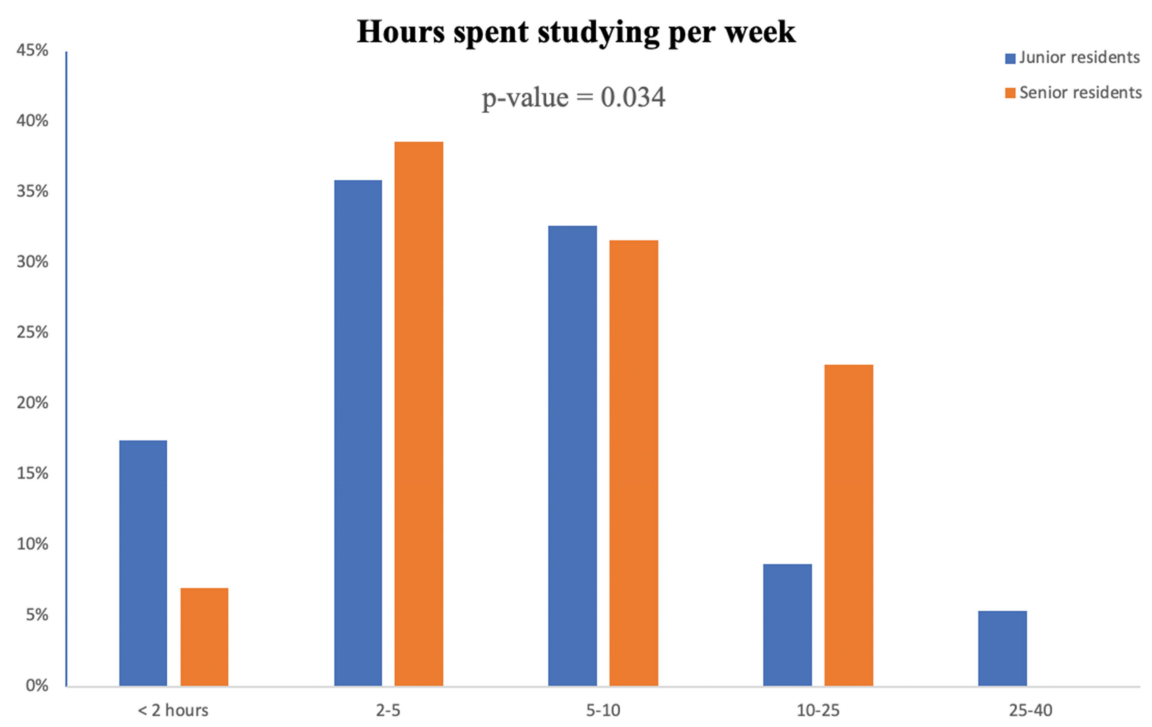

Figure I Weekly studying time. The bar graph shows the percentage of respondents at each stage of training (junior vs senior) reporting $2-40$ hours of study per week.

shown in Table 1, the mean age of doctors who responded to the survey is 28.68 years old. Most practicing urology residents in this survey are male $137(96.5 \%)$, compared to a very low number of female urology residents (3.5\%). This finding should be further investigated and further data regarding the quality of life of females who have chosen a career in urology is needed. No significant correlation could be identified in gender difference toward study habits. Previous study has demonstrated no correlation between age and gender with success on the physicians qualifying examination. ${ }^{11}$

\section{Study Habits and Residents' Performance}

Most Saudi urology residents (82.3\%) reported studying up to 10 hours per week (Table 2), which exceeds the 4 hours for surgical residents ${ }^{5}$ but is less than the 10 hours for Canadian urologists. ${ }^{3}$

In our study, juniors read more than seniors $(\mathrm{P}=0.034)$ (Figure 2). On the contrary, chief residents (PGY5) in Canada read 96\% more per week than junior residents (PGY1, PGY2) and senior residents (PGY3, PGY4). (3)

Most residents in our study reported that their training program does not prepare them well for exams (64.8\%).

Table 2 Correlation Between Marital Status or Raising Children and Weekly Study Hours

\begin{tabular}{|c|c|c|c|c|c|c|c|c|}
\hline & & \multicolumn{2}{|c|}{$\begin{array}{l}<2 \text { Hours } \\
\text { n (\%) }\end{array}$} & $\begin{array}{l}\text { 2-5 Hours } \\
\text { n (\%) }\end{array}$ & $\begin{array}{l}\text { 5-10 Hours } \\
\text { n (\%) }\end{array}$ & $\begin{array}{l}\text { I0-25 Hours } \\
\text { n (\%) }\end{array}$ & $\begin{array}{l}\text { 25-40 Hours } \\
\text { n (\%) }\end{array}$ & p-value \\
\hline \multicolumn{2}{|c|}{ All residents } & \multicolumn{2}{|c|}{$20(14)$} & $53(37.3)$ & $44(3 I)$ & $21(14.8)$ & $4(2.8)$ & \\
\hline Junior & $\begin{array}{l}\text { Single } \\
\text { Married } \\
\text { Divorced }\end{array}$ & \multicolumn{2}{|c|}{$\begin{array}{l}8(18.2) \\
8(18.6) \\
0(0.0)\end{array}$} & $\begin{array}{l}13(29.5) \\
19(44.2) \\
0(0.0)\end{array}$ & $\begin{array}{l}\text { I7 (38.6) } \\
\text { II (25.6) } \\
0(0.0)\end{array}$ & $\begin{array}{l}3(6.8) \\
4(9.3) \\
1(100.0)\end{array}$ & $\begin{array}{l}3(6.8) \\
\text { I }(2.3) \\
0(0.0)\end{array}$ & $0.263^{*}$ \\
\hline \multirow[t]{2}{*}{ Senior } & $\begin{array}{l}\text { Single } \\
\text { Married } \\
\text { Divorced }\end{array}$ & \multicolumn{2}{|c|}{$\begin{array}{l}\text { I }(10.0) \\
3(7.1) \\
0(0.0)\end{array}$} & $\begin{array}{l}0(0.0) \\
19(45.2) \\
2(100.0)\end{array}$ & $\begin{array}{l}5(50.0) \\
\text { II }(26.2) \\
0(0.0)\end{array}$ & $\begin{array}{l}4(40.0) \\
9(21.4) \\
0(0.0)\end{array}$ & $\begin{array}{l}0(0.0) \\
0(0.0) \\
0(0.0)\end{array}$ & $0.029 *$ \\
\hline & & & $\begin{array}{l}<2 \text { hours } \\
\text { n (\%) }\end{array}$ & $\begin{array}{l}2-5 \text { hours } \\
\text { n (\%) }\end{array}$ & $\begin{array}{l}5-10 \text { hours } \\
n(\%)\end{array}$ & $\begin{array}{l}10-25 \text { hours } \\
\text { n (\%) }\end{array}$ & $\begin{array}{l}25-40 \text { hours } \\
\text { n (\%) }\end{array}$ & $\mathrm{p}$-value \\
\hline Junior & Are you raising any children? & $\begin{array}{l}\text { Yes } \\
\text { No }\end{array}$ & $\begin{array}{l}4(18.2) \\
12(18.2)\end{array}$ & $\begin{array}{l}\text { II (50.0) } \\
2 \text { I (3I.8) }\end{array}$ & $\begin{array}{l}6(27.3) \\
22(33.3)\end{array}$ & $\begin{array}{l}\text { I (4.5) } \\
7(10.6)\end{array}$ & $\begin{array}{l}0(0.0) \\
4(6.1)\end{array}$ & $0.584 *$ \\
\hline Senior & Are you raising any children? & $\begin{array}{l}\text { Yes } \\
\text { No }\end{array}$ & $\begin{array}{l}3(9.1) \\
1(4.8)\end{array}$ & $\begin{array}{l}16(48.5) \\
5(23.8)\end{array}$ & $\begin{array}{l}7(21.2) \\
9(42.9)\end{array}$ & $\begin{array}{l}7(21.2) \\
6(28.6)\end{array}$ & $\begin{array}{l}0(0.0) \\
0(0.0)\end{array}$ & $0.191 *$ \\
\hline
\end{tabular}

Note: *Fisher's exact test. 


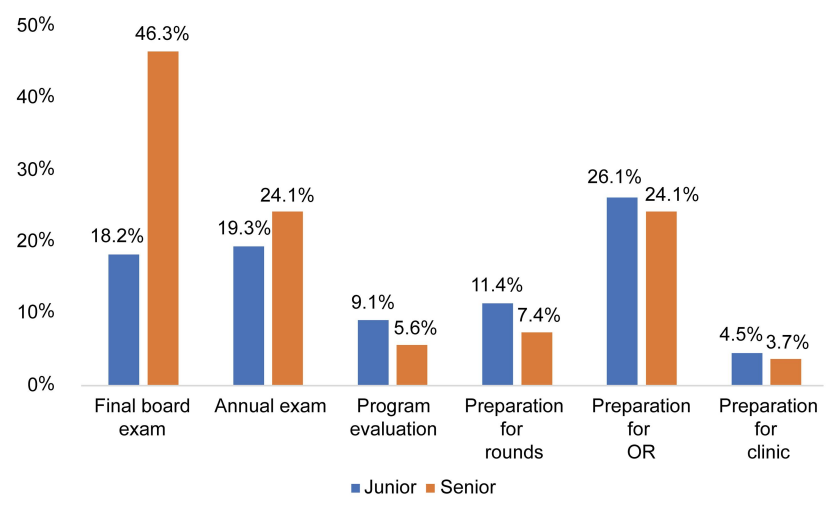

Figure 2 Motivating factors for studying. The bar graph shows the percentage of respondents at each stage of training reporting highly motivating factors for studying (Likert score $\geq 4$ ).

Abbreviation: OR, operating room.

Lower reading hours were significantly correlated with increased social activities. Many residents are married $(59.9 \%)$ and have children (62\%), and marital status significantly affects senior residents' study habits $(\mathrm{P}=0.029)$ (Table 2). Furthermore, call duties, clinical duties, and inadequate teaching were common factors negatively affecting residents' performance on board exams. Similarly, Smeds et $\mathrm{al}^{11}$ showed that the most significant barriers to studying for general surgery residents were lack of time because of clinical duties and the desire to spend time with friends or family.

\section{Motivating Factors for Studying}

The final board exam was found to be the highest motivating factor affecting urology residents' study time (Figure 2), and this matches results from American surgeons preparing for ABSITE (American Board of Surgery In-Training Examination). ${ }^{5}$ The second most motivating factors for both groups in our study were preparation for the OR and the annual end-of-year exam. Lai et al reported that exams, site-specific patient cases, and presentations are top motivators for study. ${ }^{12}$

\section{Study Material}

Most residents depend on digests and study notes as information sources (Figure 3), while they consider the Campbell-Walsh reference, which is recommended in the Saudi Urology Board curriculum, to be less useful for exam preparation. ${ }^{13}$

The least favored study resources were teaching rounds and academic activities (didactic teaching conference),

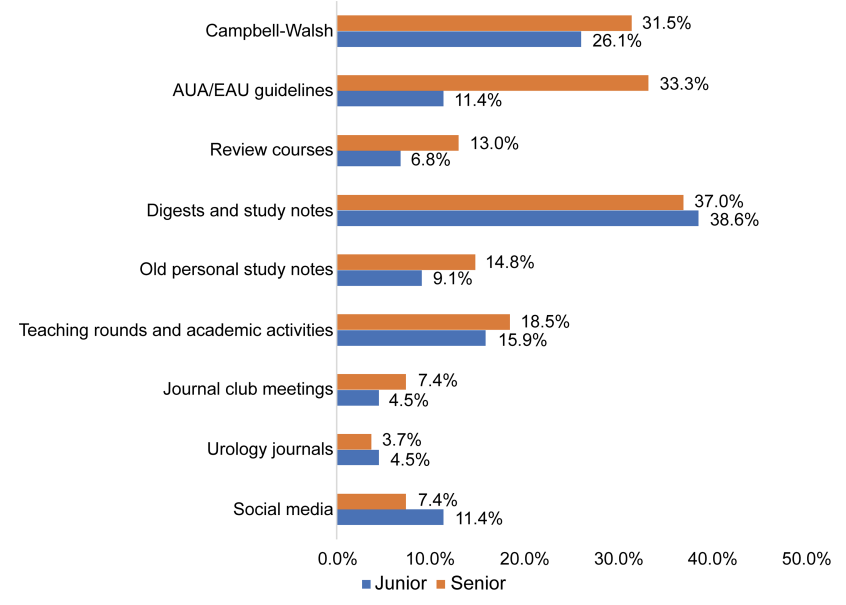

Figure 3 Useful study resources. The bar graph shows the percentage of respondents at each stage of training reporting study resources as highly useful (Likert score $\geq 4$ ).

review courses, JC meetings, urology journals, and old personal study notes.

The didactic teaching conference is a pillar of traditional medical education, currently used by $85 \%$ of American Board of Surgery programs. ${ }^{14}$ These traditional teaching methods suffer from unique disadvantages: they are fixed in time and space and often cover a given topic only once per year in a typical didactic format. Since all post-call residents are mandated to go home for rest, attendance is suboptimal. With residents in attendance paged out of conferences for patient care as often as $60 \%$ of the time ${ }^{15}$ it is no wonder that studies have failed to show learning benefits from conference attendance. ${ }^{16}$

Many residents consider presenting at JC a daunting process for which undergraduate medical education has not adequately prepared them. ${ }^{17}$ Group discussion rather than didactic presentation for JC might improve its educational value.

\section{Method of Study During Residency}

In our study, independent study showed higher percentages of acceptance among urology residents (Figure 4), which corroborates the result from Canadian urology residents ${ }^{3}$ but opposes Boehler et $\mathrm{al}^{18}$ findings that group study results in higher achievement rates among third-year American medical students. In our study, group study and dedicated lectures were the least preferred methods for both groups.

A study of 54 surgical residents over a 16-year period concluded that passive methods, such as Grand Rounds 


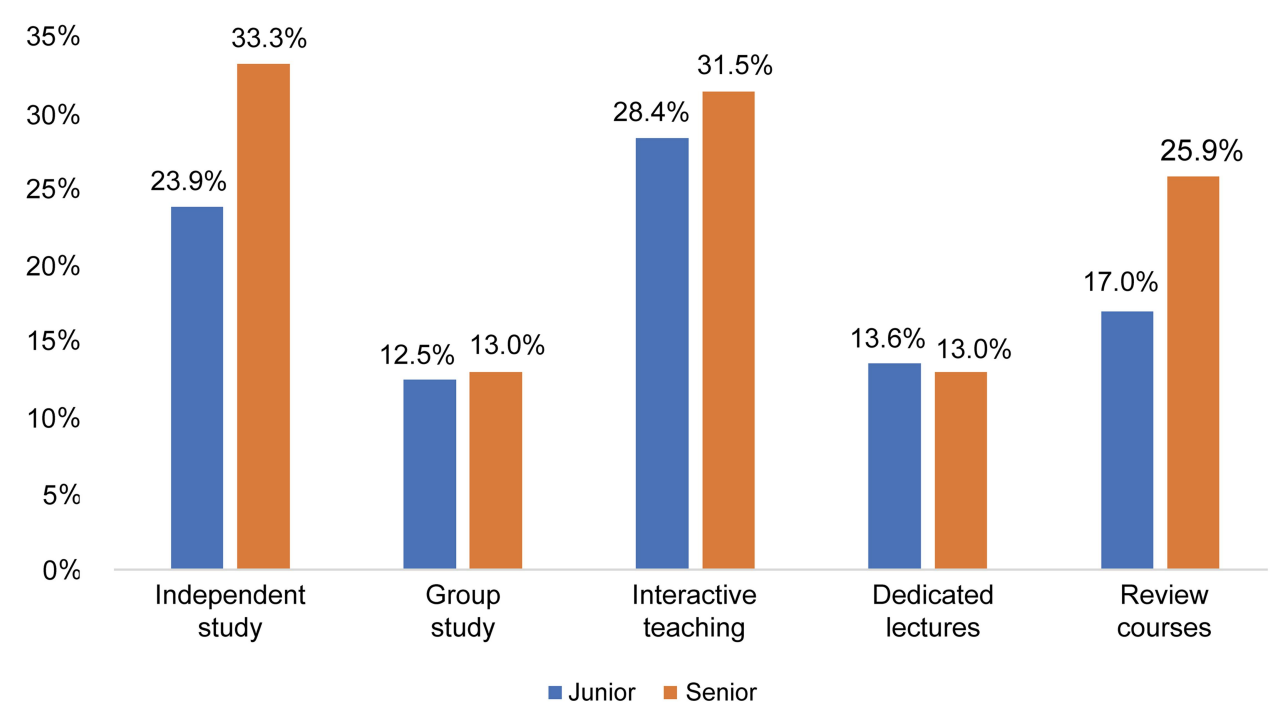

Figure 4 Preferred study methods. The bar graph shows the percentage of respondents at each stage of training reporting different study methods as highly preferred (Likert score $\geq 4$ ).

and lecture attendance, did not improve scores; independent study, however, was correlated with higher ABSITE scores. ${ }^{18}$ Good study habits, specifically delay avoidance (time management, avoiding procrastination, concentration, and preparation) and work methods (memorization skills, constructing relationships, and examination coping skills), improve ABSITE performance. ${ }^{8}$

The second most preferred study method among Saudi urology residents was interactive teaching, which has been evaluated across different specialties with promising results. $^{19-22}$ This educational technique should be used in the future if it shows more effective results than resident training. Studies confirm that interactive teaching helps residents become more active learners and more astute clinicians.

\section{Preparedness for Exams}

Most Saudi urology residents take study leave to prepare for exams, and on-call duty is their major distraction while studying. ${ }^{23}$ Family practice students reported that household responsibilities were the most common factors affecting their study and reading habits, corroborating Boehler et al. ${ }^{18}$ Sugar et al showed that January vacation schedules (where residents use their vacation time in the month prior to the examination) can significantly affect ABSITE scores which are conducted annually at the end of January. ${ }^{24}$ Hameed et al (2018) study was the first to describe residents' duty hours by surveying Saudi medical and surgical residency programs at three training centers, and it found
50\% working 60-79 hours while 30\% worked 80-plus hours per week. ${ }^{25}$

The impact of the 80-hour resident workweek on both surgical residents and attending surgeons has been examined, ${ }^{26}$ with residents' quality of life found to improve after work-hour changes. As documented by the Accreditation Council for Graduate Medical Education (ACGME) surgical case logs, the PGY5 increased their case volume, while all other residents maintained the same case volume despite the reduction in work hours. Our result supports Sugar et al finding that residents prefer to take study leave prior to exams, allowing for more intensive study just before the examination. Additionally, residents who take vacation may suffer less fatigue, thus improving examination performance. ${ }^{24}$

Residency policies in Saudi hospitals need to be changed to help residents balance on-call duty with the study time required for professional improvement.

\section{Satisfaction Level with Quality of Teaching}

Our study showed a higher satisfaction level with learning in the OR than Binsaleh et al study, in which Saudi urology residents perceived the surgical theater educational environment as less than ideal. ${ }^{27}$

In our study, the second highest level of satisfaction was with the role of senior (chief) resident/fellow in teaching. Several studies have discussed the benefits of having a chief resident and fellows enrolled in education. ${ }^{28-30}$ These studies highlight the need to prepare senior (chief) residents and fellows to participate in educational 
activities for their junior colleagues in urology training programs in Saudi Arabia.

The lowest satisfaction level was for Morbidity and Mortality Conferences (M\&MC), JC, and conference lectures. Many studies support the low satisfaction with M\&MC, ${ }^{31,32}$ which needs further improvement to engage residents in such types of educational activity in the future. Reports have mentioned some reasons for why residents are not excited to attend M\&MC including: unclear educational goals and defensiveness of residents and faculty. Most residents believe that M\&MC would be more useful if they were less defensive and blameful. ${ }^{32}$

The didactic lectures are a cornerstone of medical education. However, medical residents fail to demonstrate any learning benefit from didactic lectures in terms of standardized test scores like USMLE, ${ }^{6}$ and do not appear to be effective in changing physician performance. ${ }^{7}$ In addition, our results reflect a low satisfaction level with these sessions, while Canadian urology residents find them valuable. $^{3}$ The reason might be due to most of residents in our study depend on digests and study notes as information sources for examination preparation other than dependence in didactic lectures.

\section{Urology Residents' Overall Opinion of the Training Program}

Most Saudi urology residents (64.8\%) feel that their training program provides inadequate preparation for board exams, while $54.4 \%$ feel that it does not provide sufficient protected study time prior to board exams. This supports Binsaleh et al finding that Saudi urology residents perceived the educational environment as less than satisfactory. ${ }^{33}$

Similarly, MacNeily et al reported that approximately $68 \%$ of urology residents believed that their residency training program had not prepared them adequately for the Royal College of Physicians and Surgeons of Canada (RCPSC) examinations. ${ }^{34}$ The origins of these perceptions are probably multifactorial and are difficult to assess. It is interesting to see such percentage and reflection among urology residents and that could be due to increase in overriding tendency toward self-sufficiency and achievement between residents. Regardless of the origin of these perceptions, one should not confuse resident dissatisfaction with examination preparation with the quality of their clinical training overall, which is reflected in a high satisfaction level with learning in the OR among Saudi urology resident as mentioned in our study. The lack of dedicated time to study is a major issue in many specialties across the world. It is the responsibility of residents in the first place with the help of their educators and program directors to prepare for exams on their own time.

Regarding study habits and residents' productivity, further regulations and support systems for urology residents are required to improve their residency competencies and performance.

\section{Limitations}

This study has several limitations. The term "study" might have been misinterpreted by urology residents, since it includes a range of activities from skimming abstracts to reading full chapters. Furthermore, our study focused more on study time than on study quality and efficiency, which might have inflated the results. Other limitations of this study are the inherent biases of the design (subjectivity, recall bias, and selection bias). Finally, we did not compare the participants' responses with their academic performance.

Our study strengths include the very high response rate, with our results truly capturing a nationwide selfassessment of junior and senior residents. We also identified several deficiencies in resident training with regard to study habits. Our study can facilitate the development of effective, evidence-based curricula to maximize residents' success in future Saudi urology training programs.

\section{Conclusions}

This study provides initial insight into the study habits of Saudi urology residents. The volume of reading hours per week is low, particularly among seniors, which is linked to marital status and continuing on-call duties. A change in urology residents' lifestyle is necessary to address the problems of time management rather than study habits. Independent study and interactive teaching are the study methods most favored by urology residents, who use digests and study notes to pass exams, calling attention to the need to improve the resource reading materials available in the residency program. Further research must be conducted discussing the quality and efficiency of study rather than the quantity.

\section{Abbreviations}

ABSITE, American Board of Surgery In-Training Examination; ACGME, The Accreditation Council for Graduate Medical Education; AUA, American Urological Association; CUA, Canadian Urology Association; EAU, European Urological Association; JC, Journal Club; 
M\&MC, Morbidity and Mortality Conferences; OR, Operating Room; OSCE, Objective structured clinical examination; PGY, Postgraduate Year; RCPSC, Royal College of Physicians and Surgeons of Canada; SASP, Self-Assessment Study Program; SCFHS, Saudi Commission for Health Specialties; SPSS, Statistical Package for Social Sciences; SUA, Saudi Urology Association.

\section{Acknowledgments}

The authors would like to thank the Deanship of Scientific Research at Majmaah University for supporting this work under Project Number R-1441-166.

\section{Disclosure}

The authors report no conflicts of interest in this work.

\section{References}

1. Frank B JR, ed. The CanMEDS 2005 Physician Competency Framework. Better Standards. Better Physicians. Better Care. Ottawa: The Royal College of Physicians and Surgeons of Canada; 2005.

2. Urology Scientific Council. Saudi Board Urology Curriculum, 2014. Available from: https://www.scfhs.org.sa/MESPS/TrainingProgs/ TrainingProgsStatement/Documents/Urology\%20new.pdf. Accessed: September 16, 2014.

3. Skinner T, Ho L, Touma N. Study habits of Canadian urology residents: implications for the development of competence by design curriculum. Can Urol Assoc J. 2017;11(3):83-87. doi:10.5489/ cuaj. 4132

4. Abomelha M, Fallatah A. The current status of urological training in Saudi Arabia. Urol Ann. 2016;8(Suppl 2):S184-S188.

5. Yeh DD, Hwabejire JO, Imam A, et al. A survey of study habits of general surgery residents. $J$ Surg Educ. 2013;70(1):15-23. doi:10.1016/j.jsurg.2012.08.006

6. Fitzgerald JD, Wenger NS. Didactic teaching conferences for IM residents: who attends and is attendance related to medical certifying examination scores? Acad Med. 2003;78:84-89. doi:10.1097/ 00001888-200301000-00015

7. Davis D, Thomson O'Brien MA, Freemantle N, et al. Impact of formal continuing medical education; do conferences, workshops, rounds, and other traditional continuing education activities change physician behavior or healthcare outcomes? JAMA. 1999;282:867-874. doi:10.1001/jama.282.9.867

8. Derossis AM, Da Rosa D, Schwartz A, Hauge LS, Bordage G. Study habits of surgery residents and performance on American Board of Surgery in-training examinations. Am J Surg. 2004;188(3):230-236. doi:10.1016/j.amjsurg.2004.06.001

9. Kurtz SM, Silverman JD. The Calgary-Cambridge referenced observation guides: an aid to defining the curriculum and organizing the teaching in communication training programs. Med Educ. 1996;30 (2):83-89. doi:10.1111/j.1365-2923.1996.tb00724.x

10. Grewal S, Yeung L, Brandes S. Predictors of success in a urology residency program. J Surg Educ. 2013;70(1):138-143. doi:10.1016/j. jsurg.2012.06.015

11. Smeds MR, Thrush CR, McDaniel FK, et al. Relationships between study habits, burnout, and general surgery resident performance on the American Board of Surgery In-Training Examination. J Surg Res. 2017;217:217-225. doi:10.1016/j.jss.2017.05.034
12. Lai C, Aagaard E, Brandenburg S, Nadkarni M, Wei HG, Baron R. Brief report: multiprogram evaluation of reading habits of primary care internal medicine residents on ambulatory rotations. $J$ Gen Intern Med. 2006;21(5):486-489.

13. Saudi Board. Saudi board promotion of urology, 2016. Available at: https://www.scfhs.org.sa/MESPS/TrainingProgs/ TrainingProgsStatement/Documents. Accessed September 13, 2016.

14. Taggarshe D, Mittal V. Improving surgical residents' performance in the American Board of Surgery in training examination (ABSITE) do review courses help? The program directors' perspective. J Surg Educ. 2011;68(1):24-28. doi:10.1016/j.jsurg.2010.09.002

15. Tempelhof MW, Garman KS, Langman MK, Adams MB. Leveraging time and learning style, iPod vs realtime attendance at a series of medicine residents conferences: a randomised controlled trial . Inform Prim Care. 2009;17(2):87-94.

16. Picciano A, Winter R, Ballan D, Birnberg B, Jacks M, Laing E. Resident acquisition of knowledge during a noontime conference series. Fam Med. 2003;35(6):418-422.

17. Bowles PF, Marenah K, Ricketts DM, Rogers BA. How to prepare for and present at a journal club. Br J Hosp Med. 2013;74(10):C150C152. doi:10.12968/hmed.2013.74.Sup10.C150

18. Boehler M, Schwind R, Folse R, Dunnington G, Markwell S, Dutta M. An evaluation of study habits of third-year medical students in a surgical clerkship. Am J Surg. 2001;181(3):268-271. doi:10.1016/S0002-9610(01)00569-4

19. Htet NN, Gordon AJ, Mitarai T. Critical Care Education Day: a novel, multidisciplinary, and interactive critical care education session for emergency medicine residents. Cureus. 2020;12(1):e6785.

20. Didwania A, Farnan JM, Icayan L, et al. Impact of a video-based interactive workshop on unprofessional behaviors among internal medicine residents. J Grad Med Educ. 2017;9(2):241-244. doi:10.4300/JGME-D-16-00289.1

21. Wasser TD, Hu J, Danzig A, et al. Teaching forensic concepts to residents using interactive online modules. $J$ Am Acad Psych Law. 2020;48(1):77-83.

22. Regan L. 12 highly interactive teaching: a "HIT" with residents. Acad Emerg Med. 2008;15:S229-S230. doi:10.1111/j.1553-2712.2008. 00131_12.x

23. Johnson KH, Dayrit M, Bazargan M. The reading habits of family practice residents. Fam Med. 1997;29(7):488-491.

24. Sugar JG, Chu QD, Cole PA, Li BDL, Kim RH. Effect of January vacations and prior night call status on resident ABSITE performance. J Surg Educ. 2013;70(6):720-724. doi:10.1016/j.jsurg.2013.06.013

25. Hameed TK, Masuadi E, Al Asmary NA, Al-Anzi FG, Al Dubayee MS. A study of resident duty hours and burnout in a sample of Saudi residents. BMC Med Educ. 2018;18(1):180. doi:10.1186/s12909-018-1300-5

26. Hutter MM, Kellogg KC, Ferguson CM, et al. The impact of the 80-hour resident workweek on surgical residents and attending surgeons. Ann Surg. 2006;243(6):864-875. doi:10.1097/01.sla.0000220042.48310.66

27. Binsaleh S, Babaeer A, Rabah D, Madbouly K. Evaluation of urology residents' perception of surgical theater educational environment. J Surg Educ. 2015;72(1):73-79. doi:10.1016/j.jsurg.2014.08.002

28. Gregg SC, Eisenberg D, Duffy AJ, Longo WE. Design, management, and critical evaluation of a surgical basic/clinical science curriculum: the role of an educational chief resident. J Surg Educ. 2008;65 (1):36-42. doi:10.1016/j.jsurg.2007.09.001

29. Ning A, Gottlieb D, Lamdan RM. The chief resident for education: description of a novel academic teaching position. Acad Psychiatry. 2009;33(2):163-165.

30. Grober ED, Elterman DS, Jewett MA. Fellow or foe: the impact of fellowship training programs on the education of Canadian urology residents. Can Urol Assoc J. 2008;2(1):33-37. doi:10.5489/cuaj.522

31. Harbison SP, Regehr G. Faculty and resident opinions regarding the role of morbidity and mortality conference. Am J Surg. 1999;177 (2):136-139. doi:10.1016/S0002-9610(98)00319-5 
32. Hassanpour K, Behnaz N, Fakhri M, Pakravan M. The value of Morbidity \& Mortality (M\&M) conferences in residency training: a proposed model from an academic medical center in Iran. Patient Saf Surg. 2020;14:5. doi:10.1186/s13037-020-0231-3

33. Binsaleh S, Babaeer A, Alkhayal A, Madbouly K. Evaluation of the learning environment of urology residency training using the postgraduate hospital educational environment measure inventory. $A d v$ Med Educ Pract. 2015;6:271-277. doi:10.2147/AMEP.S81133
34. MacNeily A, Morales A. Initial assessment of a new preparatory tool for board certification in urology. Urology. 2000;55(5):647-651. doi:10.1016/S0090-4295(99)00607-X

\section{Publish your work in this journal}

Advances in Medical Education and Practice is an international, peerreviewed, open access journal that aims to present and publish research on Medical Education covering medical, dental, nursing and allied health care professional education. The journal covers undergraduate education, postgraduate training and continuing medical education including emerging trends and innovative models linking education, research, and health care services. The manuscript management system is completely online and includes a very quick and fair peer-review system. Visit http://www.dovepress.com/testimonials.php to read real quotes from published authors. 